Research Article

\title{
Toxicity Evaluation of Arsenic Nanoparticles on Growth, Biochemical, Hematological, and Physiological Parameters of Labeo rohita Juveniles
}

\author{
Muhammad Akarm Raza ${ }^{(D},{ }^{1}$ Zakia Kanwal ${ }^{1}{ }^{2}$, Ambreen Shahid, ${ }^{1}$ Shafaq Fatima, \\ Amna Sajjad, ${ }^{3}$ Saira Riaz, ${ }^{1}$ and Shahzad Naseem ${ }^{1}$ \\ ${ }^{1}$ Centre of Excellence in Solid State Physics, University of the Punjab, Lahore 54590, Pakistan \\ ${ }^{2}$ Department of Zoology, Lahore College for Women University, Lahore 54000, Pakistan \\ ${ }^{3}$ Department of Zoology, Government College University Faisalabad, Faisalabad 38000, Pakistan
}

Correspondence should be addressed to Zakia Kanwal; zakia.kanwal@lcwu.edu.pk

Received 30 August 2021; Accepted 5 November 2021; Published 16 November 2021

Academic Editor: Angela De Bonis

Copyright (c) 2021 Muhammad Akarm Raza et al. This is an open access article distributed under the Creative Commons Attribution License, which permits unrestricted use, distribution, and reproduction in any medium, provided the original work is properly cited.

\begin{abstract}
The present study aims to assess the induced nanotoxicity of arsenic nanoparticles (AsNPs) on different organs of fresh water fish Labeo rohita. AsNPs were synthesized by chemical reduction method using sodium arsenite as precursor, ice-cold sodium borohydride as reducing agent, and sodium hydroxide to adjust the solution $\mathrm{pH}$. The synthesized AsNPs were characterized by UV-Vis spectroscopy, X-ray diffraction (XRD), and scanning electron microscopy (SEM) for optical, structural, and morphological investigations. The UV-Vis absorption peaks occurring at around $300 \mathrm{~nm}$ indicated the presence of AsNPs in colloidal sample. The rhombohedral crystalline nature and metallic purity of AsNPs with crystallite size of $30 \pm 1 \mathrm{~nm}$ were confirmed by characteristic peaks of XRD pattern. The SEM micrograph revealed the almost spherical shape and $40 \pm 10 \mathrm{~nm}$ average size prepared AsNPs. For assessment of induced nanotoxicity, juveniles of Labeo rohita (L. rohita) were exposed to three different concentrations of AsNPs (namely, 1, 10, and $20 \mathrm{mg} / \mathrm{L}$ ) for 30 days ( $n=15$ per group), and the control fish was kept untreated. It was observed that the routine behavior activities (such as swimming, mutual interactions, and feed intake) were affected by AsNPs. The growth of AsNPs treated fish was found retarded as compared to the control fish. Total erythrocyte count, total leukocyte count, and hemoglobin and hematocrit values were low in the AsNPs treated fish. Immunobiochemical assays revealed that protein level was altered in the AsNPs treated fish. The levels of antioxidant enzymes catalase and superoxide dismutase were low in the treated fish. The histological alteration induced by AsNPs in liver, gills, and kidneys demonstrated the damage in form of glomerulus shrinkage, vacuolation, inflammation, necrosis, lamellar disorganization, and hemorrhage in comparison with untreated fish. The results of the present study indicate that AsNPs exposure causes behavior, growth, hematology, immunobiochemical, and histological shortcomings in L. rohita.
\end{abstract}

\section{Introduction}

Environmental toxicology includes the study of hazardous effects of chemicals on living organisms in the environment. Developing technologies and industries are the main cause of environmental pollution that is particularly harmful to aquatic life because industrial and agricultural wastes are usually released into water resources [1]. It is, therefore, very important to recognize and oversee the sources of environmental pollution, to handle their harmful effects on aquatic ecosystems. Fish is considered very sensitive to changes in their environment as they are frequently exposed to the pollutants present in surrounding waters through gills and skin and, therefore, can be used as bioindicator for the determination of water quality $[2,3]$. Besides being the main source of proteins for humans through its meat, fish can also be a major vector for the transfer of pollutants to humans due to the presence of contaminants in its surrounding 
water. If exposed to these contaminants for a longer time, fish can be affected sublethally $[4,5]$. Nowadays, nanotechnology is one of the most emerging fields with a lot of scope in biomedical and analytical sciences [6]. Nanotechnology deals with different structures that have dimensions of the order of $10^{-9}$ meters. When the dimension of the matter is reduced to nanorange, the surface area is increased in comparison to its volume. Owing to large surface to volume ratio, nanostructures have great applications in many fields [7]. Besides these advantages, there also exist some concerns to nanotechnology. Due to human activities such as improper disposal of wastes, metallic nanoparticles enter aquatic ecosystems and result in serious threats to aquatic animals. Different nanoparticles have been reported to cause adverse effects on aquatic organisms; for instance, iron oxide nanoparticles alter the hemoglobin content, red blood cells and white blood cells number, hematocrit, blood glucose, $\mathrm{Na}^{+}, \mathrm{K}^{+}, \mathrm{Cl}^{-}$, and plasma protein in Labeo rohita [8]. Nickel nanoparticles cause decrease in antioxidant enzymes in liver and gills of Oreochromis mossambicus. Nickel nanoparticles also cause hyperplasia of gill epithelium, epithelial lifting, and epithelial rupture. Necrosis, vacuolar degeneration, edema, and muscle fibers' splitting was observed in skin of Oreochromis mossambicus [9]. Similarly, high doses of silver nanoparticles (AgNPs) cause bioaccumulation and tissue damage due to changes in the concentration of ACP and ALP enzymes, damage to gills primary lamella and blood vessels, and vacuolar degeneration in liver [10]. Silver nanoparticles can induce severe histopathological changes in zebrafish. They accumulate in tissues of liver and gills and cause damage to tissues [11]. Cobalt oxide nanoparticles cause injuries like hyperplasia, lamellar fusion, hypertrophy, necrosis, increased mucous secretion, and aneurism in zebrafish which caused breathing disorder and death [12]. We previously have found that silver, nickel, cobalt, and chromium oxide nanoparticles cause various levels of toxicity in Labeo rohita on growth, hematological, histological, and biochemical indices [13].

Arsenic nanoparticles (AsNPs) have been considered good candidates for cancer treatment and have shown good cytotoxic potential against breast cancer cells [14]. In another study, arsenic trioxide nanoparticles $\left(\mathrm{As}_{2} \mathrm{O}_{3} \mathrm{NPs}\right)$ were reported to inhibit acute promyelocytic leukemia and PTEN/AKT mediated apoptosis [15]. $\mathrm{As}_{2} \mathrm{O}_{3} \mathrm{NPs}$ were also shown to cause strong apoptosis and cytotoxic effect against NB4 tumor cells by inhibiting Bcl-2 expression [16]. Keeping in view AsNPs' emerging use in the medical and industrial applications, it is very important to ascertain their effects on living tissues. Arsenic in bulk form is considered as one of the top pollutants present in natural waters, produced due to some geological processes and industrialization such as smelting and mining $[17,18]$. It is carcinogenic in nature and causes genotoxicity, mitochondrial damage, DNA fragmentation, reduction in protein content, defects in enzyme activities, reactive oxygen species elevation, and apoptosis induction [19-24].

Blood analysis is an important biological tool to evaluate the effects of pollutants on fish. The hematological profile of fish may indicate the alternations in aquatic ecosystems caused by environmental pollutants and thus act as pathophysiological indicator to detect the health status of fish. The levels of hemoglobin concentration $(\mathrm{Hb})$, hematocrit (Hct), red blood cell (RBC), and mean corpuscular hemoglobin concentration (MCHC) are used to check oxygen-carrying capacity of the blood and immune responses. Moreover, by monitoring the white blood cells (WBC) and thrombocytes (TC) along with aforementioned blood parameters, sublethal effects of toxicants can also be predicted [25, 26]. Furthermore, blood variables are good indicators for disease diagnosis and assess the overall health status of fish. Blood profiles very sensitive to different changes are related to nutrition, internal and external environmental stressors, and diseases $[27,28]$. Although a lot of data is available about the toxic effects of bulk arsenic on animal life, very little data exists on the toxicity of AsNPs to aquatic species and their associated ecological consequences. To the best of our knowledge, there is no study available on the toxic potential of AsNPs on fish. So, the present study is designed to examine the effects of AsNPs on the growth and hematobiochemical parameters of fresh water fish (Labeo rohita), which is commercially and economically important fish.

\section{Materials and Methods}

2.1. AsNPs Synthesis. AsNPs were prepared by wet chemical reduction method already reported by $\mathrm{Pal}$ et al. [29] with some modifications. Sodium arsenite $\left(\mathrm{NaAsO}_{2}\right)$ was used as precursor salt; it was dissolved in water to prepare a $30 \mathrm{mM}$ stock solution. A second aqueous stock solution $(300 \mathrm{mM})$ of sodium borohydride $\left(\mathrm{NaBH}_{4}\right)$ was prepared and stored at $5^{\circ} \mathrm{C}$. For the synthesis process, $4.54 \mathrm{ml}$ of $\mathrm{NaAsO}_{2}$ stock solution was added to $100 \mathrm{ml}$ of water, and $\mathrm{pH}$ was maintained between 7 and 9 by adding appropriate amount of sodium hydroxide $(\mathrm{NaOH}) .5 \mathrm{ml}$ of ice-cold $\mathrm{NaBH}_{4}$ was added to the precursor solution; the whole mixture stood for 2 hours (at room temperature) and was then heated for $20 \mathrm{~min}$ at $60^{\circ} \mathrm{C}$. Later, it was cooled to room temperature.

2.2. Characterizations of Prepared AsNPs. We used ultraviolet-visible spectroscopy (Shimadzu, UV-1800, Japan) in the wavelength range of $300-700 \mathrm{~nm}$ to study the optical response of colloidal AsNPs. The X-ray powder diffractometer (XRD; JSX $3201 \mathrm{M}$, Jeol, Japan) was used to study the structural properties of AsNPs. The $\mathrm{Cu}-\mathrm{K} \alpha$ line radiation having wavelength $1.5406 \times 10^{-10} \mathrm{~m}$ was used in XRD. For XRD, a thick film of colloidal sample was achieved by drop casting method on the glass slide followed by drying at room temperature. To study the size and shape of prepared AsNPs, scanning electron microscope (Nova NanoSEM 450, USA) was used. For SEM analysis, again, drop casting technique was used to obtain enough AsNPs amount on a clean piece of glass slide. A thin coating of gold was deposited on the sample before conducting SEM to avoid any charging effects.

2.3. Fish and Experimental Setup. Juveniles of Labeo rohita (L. rohita) were procured from local fish hatchery (Muridke) and brought to the laboratory in well-aerated 
plastic bags. Fish was examined by the experts of Department of Zoology, Lahore College for Women University, Lahore, Pakistan, and declared healthy. No disease symptoms or any lesions were found on the fish. The healthy specimens were then transferred to $60 \mathrm{~L}$ glass aquaria containing tap water. Fish were treated in compliance with the local animal welfare regulations (Zoology/LCWU/5729) of the host university (Lahore College for Women University). The water quality parameters are listed in Table 1. A constant aeration was supplied to the aquaria to keep optimum dissolved oxygen. About 30\% water was exchanged with fresh water at the daily basis throughout the experimental period, to remove any uneaten or fecal material. The fish were randomly allocated into four groups in triplicate at the density of 15 fish in each group. Group 1 (G1) contained control untreated fish, Group 2 (G2) was treated with $1 \mathrm{mg} / 1$ of AsNPs, Group 3 (G3) was treated with $10 \mathrm{mg} / \mathrm{l}$ of AsNPs, and Group 4 (G4) was treated with $20 \mathrm{mg} / \mathrm{l}$ of AsNPs.

2.4. Behavioral and Growth Analysis. Fish behavior was examined after AsNPs treatment. Swimming, interactions, and feed intake were observed. The survival rate of fish was also recorded. In order to study fish growth, length and weight were measured before and after the experiment.

2.4.1. Hematological Indices. At the end of the experimental period, fish were anesthetized with clove oil $(100 \mu \mathrm{g} / \mathrm{l})$ and blood was extracted with syringe. EDTA was added to blood to prevent coagulation. Total erythrocyte count (TEC) and total leukocyte count (TLC) were counted by using a hemocytometer. Hemoglobin $(\mathrm{Hb})$ was measured by Cyanmethemoglobin method using Drabkin's fluid. Absorbance was taken at $540 \mathrm{~nm}$ with spectrophotometer. Hematocrit (Hct) value was taken by using microhematocrit tubes as described by Dacie and Lewis [30].

2.5. Immunobiochemical Analysis. Serum was obtained for immunobiochemical parameters by clotting blood at room temperature for one hour following centrifugation at $3000 \mathrm{rpm}$ for $15 \mathrm{~min}$. Total protein (TP) and albumin (ALB) were calculated by using TP and ALB kit (Crescent Diagnostics, Saudi Arabia), respectively. Globulin (GLB) value was obtained by subtracting ALB from TP. For analyzing catalase (CAT) and superoxide dismutase (SOD) activities, liver tissue was snap-frozen into liquid nitrogen and stored at $-40^{\circ} \mathrm{C}$. Tissues were washed with chilled PBS, homogenized, and centrifuged at $4^{\circ} \mathrm{C}$ for $15 \mathrm{~min}$ at $12000 \mathrm{rpm}$. Supernatant was used to calculate the values of CAT and SOD spectrometrically.

2.6. Histological Evaluation. Kidney, gill, and liver tissues were fixed in $10 \%$ buffered formalin. All the tissues were dehydrated in graded absolute ethanol solutions (ascending order: $25 \%, 50 \%, 75 \%$, and $100 \%$ ) for 15 min each. Paraffin wax was used to entrench the dehydrated tissues for section cutting. Sections of $6-8 \mu \mathrm{m}$ thickness were obtained by
TABLE 1: The physical and chemical parameters of water (Mean$\pm \mathrm{SE}$ ) measured during experimental period.

\begin{tabular}{lc}
\hline Water parameter & Mean $\pm \mathrm{SE}$ \\
\hline Temperature $\left({ }^{\circ} \mathrm{C}\right)$ & $26.91 \pm 2.15$ \\
Dissolved oxygen $(\mathrm{mg} / \mathrm{L})$ & $6.1 \pm 1.5$ \\
Ammonium NH$_{3}(\mathrm{mg} / \mathrm{L})$ & $0.17 \pm 0.09$ \\
Chloride $(\mathrm{mg} / \mathrm{L})$ & $10.2 \pm 1.85$ \\
Nitrate $(\mathrm{mg} / \mathrm{L})$ & $0.05 \pm 0.02$ \\
$\mathrm{pH}$ & $7.2 \pm 1.6$ \\
\hline
\end{tabular}

cutting tissues on rotatory microtome (ERM-2301). Tissue sections were deparaffinized with xylene, rehydrated in graded absolute ethanol (in descending order: $75 \%, 50 \%$, $25 \%$, and $0 \%$ ), and mounted on slides with DPX (distyrene, plasticizer, and xylene). Staining of the sections was done with HE (Hematoxylin, Eosin). Pictures of the slides were taken with Trinocular Camera fitted digital microscope (E200, Nikon Japan Eil-12).

2.7. Statistical Analysis. Data is presented as mean with error bars indicating standard error of the mean. One-way analysis of variance (ANOVA) was used to calculate the statistically significant differences between groups. Graphs were made in Microsoft Excel program. GraphPad Prism (ver.7.03, USA) was used to find significant differences between groups.

\section{Results}

3.1. Synthesis Mechanism of AsNPs. In the synthesis process of AsNPs by wet chemical reduction approach, solution reaction went through different phases which can be observed by the change of color of the solution as shown in Figure 1. The potential mechanism for the formation of AsNPs can be explained as follows: first of all, as precursor $\left(\mathrm{NaAsO}_{2}\right)$ is dissolved in the water, arsenite ions $\left(\mathrm{As}^{3+}\right)$ are produced in the solution and no color change occurred in the solution (Figure 1(a)). Before introducing the reducing agent $\left(\mathrm{NaBH}_{4}\right)$, the $\mathrm{pH}$ of the solution was maintained up to $7-9$ by the addition of $\mathrm{NaOH}$. The value of $\mathrm{pH}$ matters in this case because, at lower $\mathrm{pH}(<4)$, the same reducing agent $\left(\mathrm{NaBH}_{4}\right)$ can reduce $\mathrm{As}^{3+}$ to $\mathrm{AsH}_{3}$ instead of neutral arsenic atoms (As0) [29]. The reduction process started as the $\mathrm{NaBH}_{4}$ solution was added into the precursor solution and arsenite ions $\left(\mathrm{As}^{3+}\right)$ reduced to free As-atoms $\left(\mathrm{As}^{0}\right)$ which can be noticed from the color charge of the solution (Figure 1(b)). Change in color of solution with the passage of time actually indicated the different stages of nucleation and growth. The formation of As-nuclei started owing to the accumulation of free As-atoms $\left(\mathrm{As}^{0}\right)$ under action of van der Waals interactions and Brownian movement. In the synthesis of NPs during reduction method, both nucleation and growth process may happen side by side [31, 32] Heating the solution may further accelerate the reaction process. The further change in solution color indicated the different phases during formation of AsNPs as shown in Figures 1(c)-1(e). 


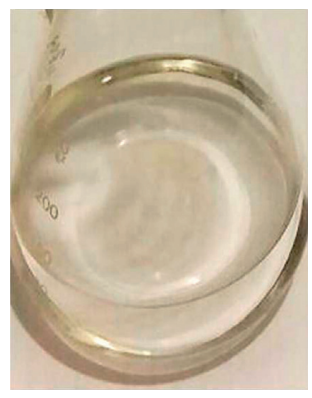

(a)

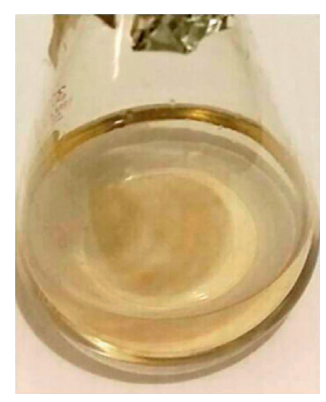

(b)

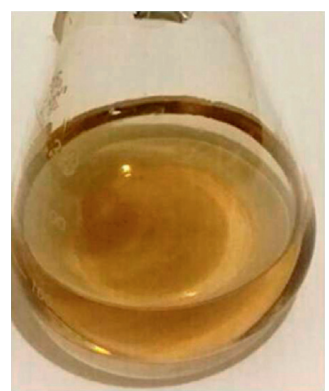

(c)

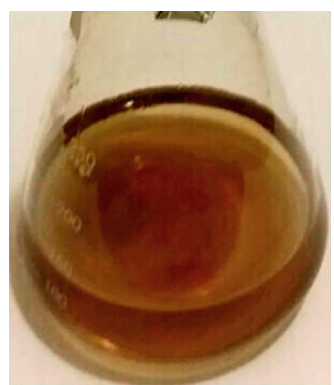

(d)

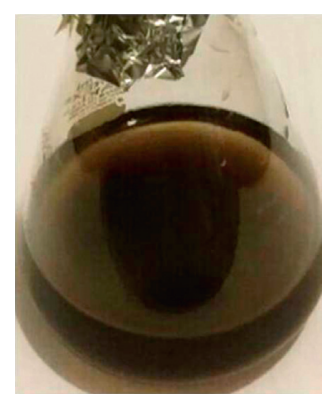

(e)

Figure 1: Different stages during the synthesis of AsNPs. (a) Transparent precursor solution indicated no color by the As ${ }^{3+}$ ions formation. (b) Color of solution changed to light yellow by the addition of reducing agent due to the reduction process. (c-e) Further color change from light yellow to dark brown is owing to the nucleation and growth process leading to the formation of AsNPs.

\subsection{Characterization Analysis of Synthesized AsNPs}

3.2.1. UV-Visible Spectroscopy Analysis. UV-Vis showed structural and optical information of AsNPs. Metallic nanoparticles exhibit a characteristic absorption spectrum that lies within the ultraviolet and visible region which is known as surface plasmon resonance (SPR) [33]. Figure 2(a) shows the UV-Vis spectrum of synthesized AsNPs showing an increase in absorption of AsNPs as wavelength corresponds to smaller values and showed the maximum absorption at around $300 \mathrm{~nm}$. The peak maximum corresponds to the formation of AsNPs and is consistent with already reported literature [29].

3.2.2. XRD Analysis. Structural analysis of our sample was carried out by X-ray diffractometer to identify the crystalline nature of AsNPs. The obtained XRD pattern is shown in Figure 2(b); seven peaks could be discerned to the reflection planes (003), (101), (012), (104), (110), (006), and (113) of the rhombohedral structure of pure metallic AsNPs [34]. Crystalline size according to Scherrer formula [35] was $D=30 \pm 1 \mathrm{~nm}$.

3.2.3. SEM Analysis. Morphology and size distribution of AsNPs are shown in SEM micrograph (Figure 2(c)). Almost all particles have spherical shapes. Most of the particles have uniform size range between 30 and $40 \mathrm{~nm}$; however, few smaller sized particles also appeared. The average particles size is $40 \pm 10 \mathrm{~nm}$.

3.3. Behavioral Changes. Behavior of both control and AsNPs exposed groups was examined to determine behavioral differences. This behavior parameters included swimming activity, mutual interactions, and feed uptake. The observation showed that the routine swimming of fish was greatly disturbed by AsNPs in comparison to the control group. The treated group fish were less active and stayed close to the bottom of the tank. The feeding activity was poor. Survival rate of fish was also found to be affected in AsNPs treated fish. The documentation of behavior and survival is presented in Table 2 .
3.4. Growth Studies. The length and weight of both groups were recorded before and after the experiment. A difference was recorded in the overall growth between control and AsNPs treated groups. Clearly, AsNPs depressed the growth of fish in terms of both weight and length (Table 3). Following growth, parameters were recorded: weight gain, percentage weight gain (\%), specific growth ratio (\%), feed conversion ratio, condition factor, and length gain.

3.5. Hematological Indices. Blood cells were adversely affected by exposure to AsNPs. RBCs and WBCs were determined in control and AsNPs treated groups using a hemocytometer. Both RBCs and WBCs were found to be low in abundance in AsNPs treated group. Hb and Hct values also decreased in the treated groups. These results showed that AsNPs adversely affected blood chemistry of the fish (Table 4).

3.6. Immunobiochemical Analysis. TP, ALB, GLB, A/G ratio, CAT, and SOD activities were measured in control and AsNPs treated groups. The level of TP was significantly different between control G3 and G4 groups. Level of albumin was high in AsNPs treated fish. The difference was significant between control and G4. Globulin level was not much different in control and G2 but was significantly low in G3 and G4 in comparison to G1. The A/G ratio was high in G3 and G4 groups (Figure 3). Catalase activities were decreased in all AsNPs treated groups and were significantly low in G3 and G4. SOD activities were also significantly low in G3 and G4 groups (Figure 3).

3.7. Histology. To observe the histological effects of AsNPs on fish organs, kidney, gills, and liver tissues were selected. These organs are routinely used for assessing the toxic potential of various molecules on living cells and tissues. Kidney histology revealed that AsNPs caused vacuolation, glomerulus shrinkage, inflammation, necrosis, and epithelial desquamation. In gills, AsNPs caused degeneration, hemorrhage, lamellar fusion, disorganization, aneurysm, and blood congestion. In liver, AsNPs caused vacuolation, necrosis, blood congestion, and inflammation (Figure 4). 


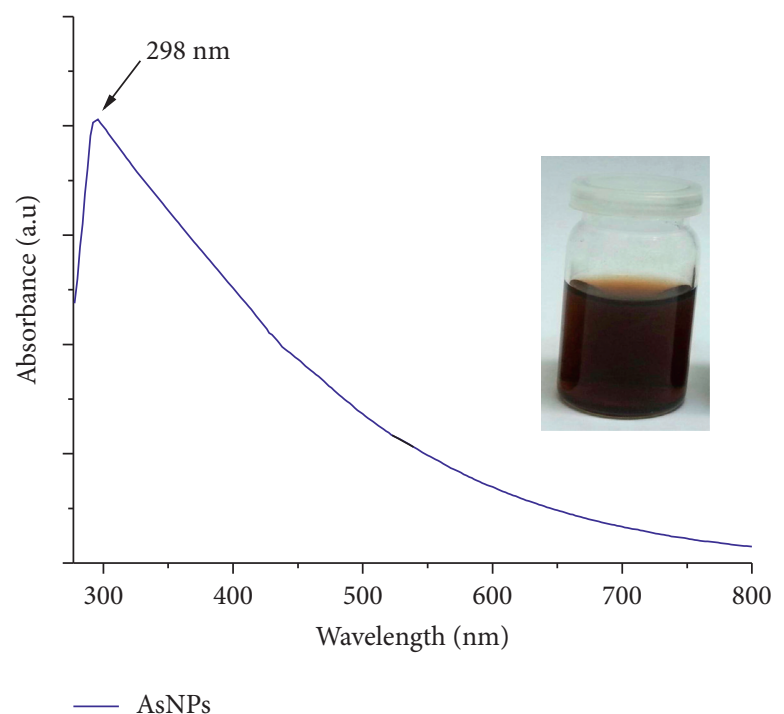

(a)

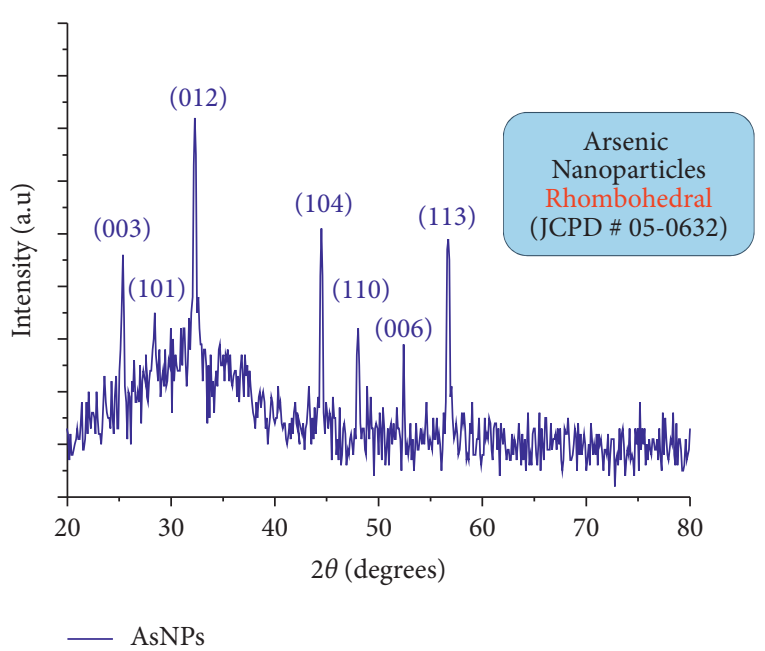

(b)

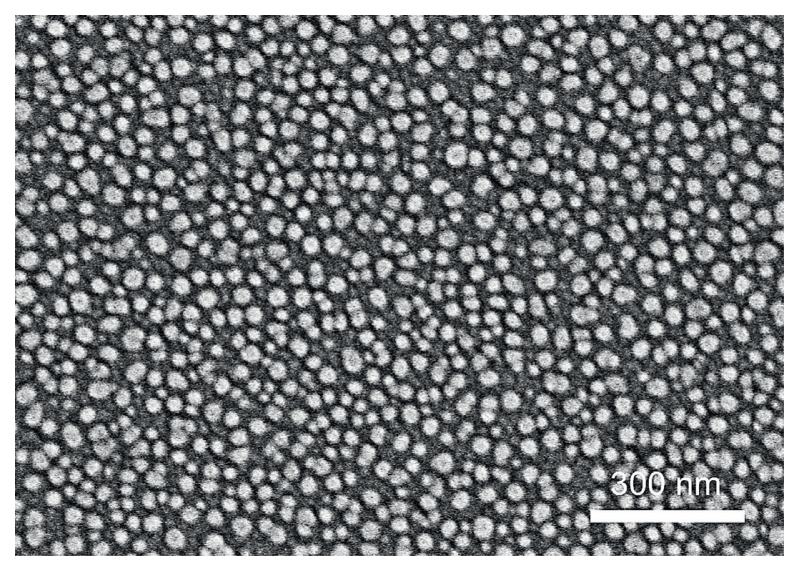

(c)

FIgURE 2: (a) Ultraviolet-visible (UV-Vis) absorption spectra of AsNPs show maximum absorption at around $300 \mathrm{~nm}$. (b) XRD pattern of AsNPs indicating rhombohedral crystalline nature. (c) SEM image of showing spherical morphology of AsNPs.

TABle 2: A. Behavioral manifestation of fish. ++: good activity, +: slightly low activity, + - : very low activity, -: loss of activity. B. Survival rate of fish.

\begin{tabular}{lcccc}
\hline A. Behavior categories & G1 & G2 & G3 & G4 \\
\hline Swimming & ++ & + & +- & +- \\
Mutual interactions & ++ & + & - & +- \\
Feed intake & ++ & ++ & + & + \\
$\begin{array}{l}\text { B. Survival rate } \\
\text { Percentage survival (\%) }\end{array}$ & 100 & 100 & 90 & 65 \\
\hline
\end{tabular}

\section{Discussion}

Although nanoparticles have been found to be dispersed widely in nature (air, soil, and water), less meticulous in vivo studies have been carried out concerning their long-term detrimental effects on environment. It is arbitrarily known that nanoparticles cause various adverse health effects on animals but the information about the mechanism of action and data about the qualitative and quantitative impacts are lacking. Nanoparticles can enter the animal bodies through inhalation, injection, dermal route, and ingestion and can ultimately be accumulated in the tissues [36].

From these entry points, they can further reach the circulatory and lymphatic systems. When nanoparticles are procured in water as their final exit areas, aquatic animals directly engulf them with water or they can enter their bodies, for example, in fish through gills. Bulk arsenic toxicity caused by contaminated water has been reported from many countries such as India and Bangladesh [37].

We exposed $L$. rohita juveniles to different concentrations of AsNPs (1, 10, and $20 \mathrm{mg} / \mathrm{L}$ ) for a period of 30 days. Firstly, the behavior of fish was noted. We found that the fish treated with AsNPs showed disturbed patterns of behavior activities (Table 2). In AsNPs treated groups, swimming and mutual interactions were highly disturbed particularly at higher concentrations. Feed intake was also reduced in the AsNPs exposed fish. All these behavior changes may be attributed to the transfer of NPs to the brain which results in damage to the texture of brain and altered metabolism. As these effects are 
TABle 3: Growth parameters: G1 (control), G2 (AsNPs $1 \mathrm{mg} / \mathrm{l}$ ), G3 (AsNPs $10 \mathrm{mg} / \mathrm{l}$ ), and G4 (AsNPs $20 \mathrm{mg} / \mathrm{l}$ ). Values with a different superscript in the same row are significantly different.

\begin{tabular}{|c|c|c|c|c|}
\hline Growth parameter & G1 & G2 & G3 & G4 \\
\hline Weight gain & $15.5 \pm 0.9^{\mathrm{a}}$ & $12.7 \pm 0.7^{b}$ & $7.9 \pm 0.4^{\mathrm{c}}$ & $4.9 \pm 0.9^{\mathrm{d}}$ \\
\hline Percentage weight gain (\%) & $42.6 \pm 1.9^{\mathrm{a}}$ & $35.4 \pm 2.3^{\mathrm{b}}$ & $21.5 \pm 1.4^{\mathrm{c}}$ & $13.8 \pm 1.6^{\mathrm{d}}$ \\
\hline Specific growth ratio (\%) & $2.8 \pm 0.3^{\mathrm{a}}$ & $2.6 \pm 0.5^{\mathrm{a}}$ & $2.1 \pm 0.6^{\mathrm{b}}$ & $1.6 \pm 0.5^{\mathrm{b}}$ \\
\hline Feed conversion ratio & $0.7 \pm 0.1^{\mathrm{a}}$ & $0.9 \pm 0.2^{\mathrm{a}}$ & $1.5 \pm 0.5^{\mathrm{b}}$ & $2.4 \pm 0.6^{\mathrm{c}}$ \\
\hline Condition factor & $2.1 \pm 0.6^{\mathrm{a}}$ & $2.1 \pm 0.8^{\mathrm{a}}$ & $2.4 \pm 0.9^{\mathrm{a}}$ & $1.7 \pm 0.6^{\mathrm{b}}$ \\
\hline Length gain & $1.2 \pm 0.3^{\mathrm{a}}$ & $0.8 \pm 0.2^{\mathrm{b}}$ & $0.6 \pm 0.2^{\mathrm{b}}$ & $0.7 \pm 0.1^{\mathrm{b}}$ \\
\hline
\end{tabular}

TABle 4: Summary of hematological parameters: G1 (control), G2 (AsNPs 1 mg/l), G3 (AsNPs 10 mg/l), and G4 (AsNPs 20 mg/l). Values with a different superscript in the same row are significantly different.

\begin{tabular}{|c|c|c|c|c|}
\hline Hematological indices & G1 & G2 & G3 & G4 \\
\hline Total erythrocyte count $\left({ }^{*} 10^{6} / \mathrm{mm}^{3}\right)$ & $314 \pm 25^{\mathrm{a}}$ & $295 \pm 21^{\mathrm{a}}$ & $275 \pm 11^{\mathrm{c}}$ & $267 \pm 14$ \\
\hline Total leukocyte count $\left({ }^{*} 10^{4} / \mathrm{mm}^{3}\right)$ & $19 \pm 2^{\mathrm{a}}$ & $17 \pm 4^{\mathrm{a}}$ & $12 \pm 2^{\mathrm{c}}$ & $13 \pm 1^{\mathrm{d}}$ \\
\hline Hemoglobin $(\mathrm{g} / \mathrm{dl})$ & $11.2 \pm 1.2^{\mathrm{a}}$ & $10.3 \pm 3.2^{\mathrm{a}}$ & $9.6 \pm 2.3^{\mathrm{a}}$ & $7.2 \pm 1.9^{\mathrm{a}}$ \\
\hline Hematocrit $(\%)$ & $18 \pm 2^{\mathrm{a}}$ & $18.7 \pm 1.4^{\mathrm{a}}$ & $16.3 \pm 3.1^{\mathrm{a}}$ & $12.4 \pm 2.1^{\mathrm{a}}$ \\
\hline Total erythrocyte count $\left({ }^{*} 10^{6} / \mathrm{mm}^{3}\right)$ & $314 \pm 25^{\mathrm{a}}$ & $295 \pm 21^{\mathrm{a}}$ & $275 \pm 11^{c}$ & $267 \pm 14$ \\
\hline
\end{tabular}

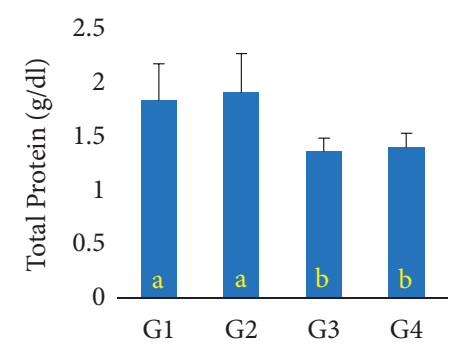

(a)

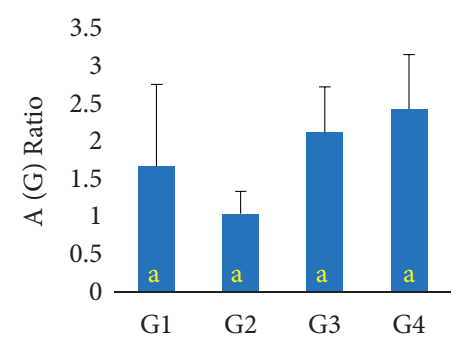

(d)

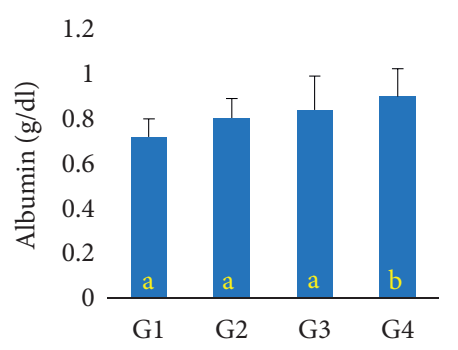

(b)

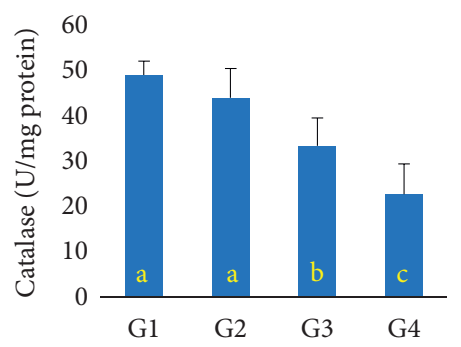

(e)

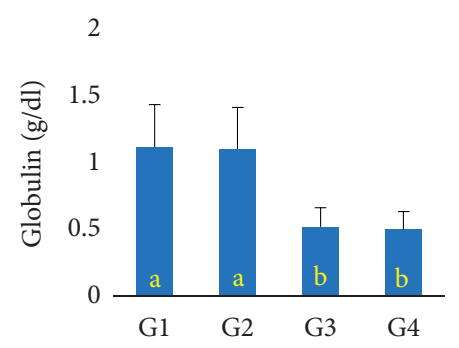

(c)

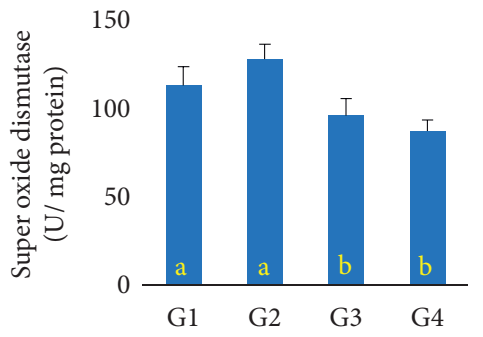

(f)

Figure 3: (a) Total protein level was comparable between control and G1. It was significantly low in G3 and G4. (b) Albumin was high at all three concentrations in AsNPs treated groups. The difference was significant between G1 and G4. (c) Globulin was significantly low in G3 and G4 groups as compared to G1 group. (d) A/G ration was high in G3 and G4. (e) Catalase was low in all AsNPs treated groups with the lowest in G4. (f) Superoxide dismutase level was significantly low in G3 and G4 groups. Columns showing different letters are significantly different $\left({ }^{*} p<0.05\right)$ (G1: control, G2: $1 \mathrm{mg} / \mathrm{l}, \mathrm{G} 3: 10 \mathrm{mg} / \mathrm{l}$, and G4: $\left.20 \mathrm{mg} / \mathrm{l}\right)$.

concentration-dependent, that is why we see different degrees of behavior changes at different concentrations [38-40].

High concentration of AsNPs was found to be fatal for fish as survival rate decreased to $90 \%$ and $65 \%$ in G3 and G4 groups, respectively (Table 2). Lethal concentrations vary for different types of nanoparticles, exposure periods, and the animal species type. For example, LC50 concentrations for AgNPs, CuNPs, and NiNPs were determined to be $2.9 \mathrm{mg} / \mathrm{l}$, $3.8 \mathrm{mg} / \mathrm{l}$, and $>400 \mathrm{mg} / \mathrm{l}$, respectively, for $96 \mathrm{~h}$ in adult zebrafish [41]. In another study, AgNPs (100 mg/kg) were applied to L. rohita for 7 days, and the concentration was found to be nonlethal [10]. In our previous work, we found
$100 \%$ survival rate of L. rohita treated with AgNPs, NiNPs, and $\mathrm{Co}_{3} \mathrm{O}_{4} \mathrm{NPs}$ while survival was $86 \%$ in fish treated with $\mathrm{Cr}_{3} \mathrm{O}_{4} \mathrm{NPs}$ for a period of 21 days with $25 \mathrm{mg} / \mathrm{l}$ concentration of all the NPs.

Growth of fish can be influenced by stressors in surrounding environment. They affect appetite of fish, thereby causing low feed intake and low growth increment. We observed significantly reduced growth in AsNPs treated groups as compared to control (Table 3). Lesser weight gain in mice and fish exposed to carbon nanotubes, gold, and plastic NPs has already been reported $[36,42,43]$. This might be due to low food digestibility 


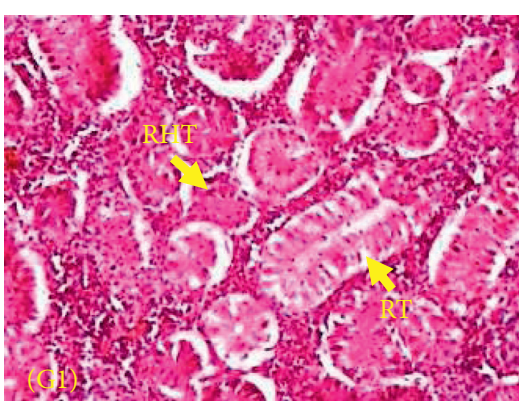

(a)

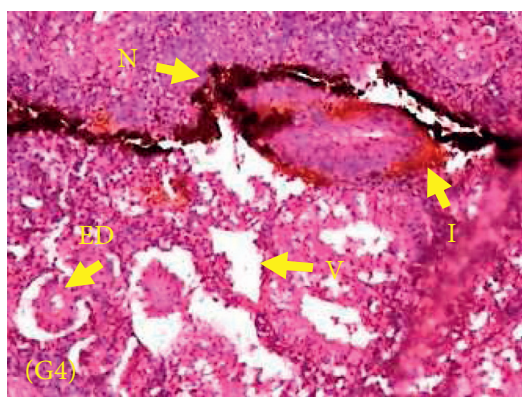

(d)

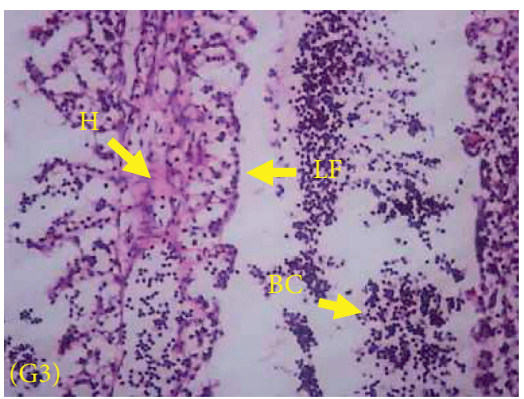

(g)

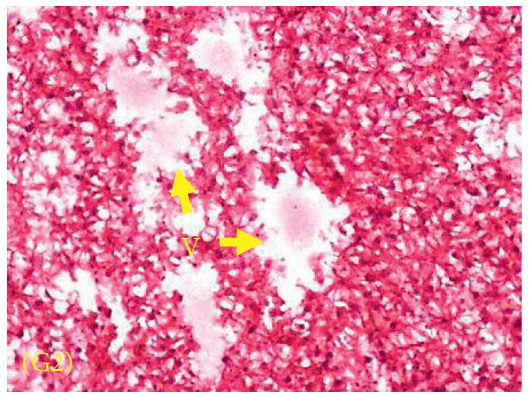

(j)

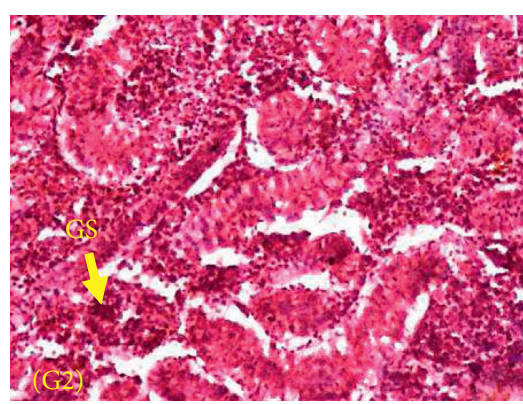

(b)

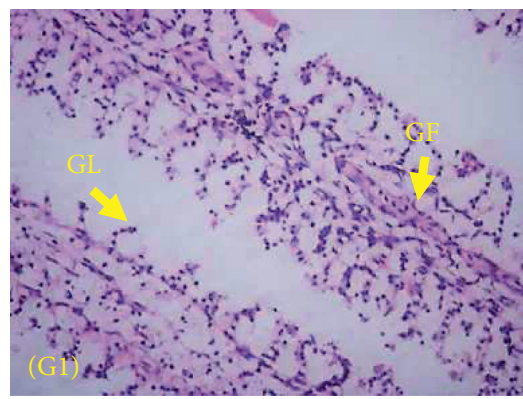

(e)

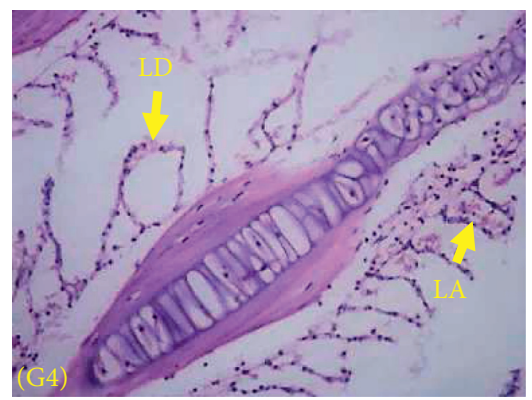

(h)

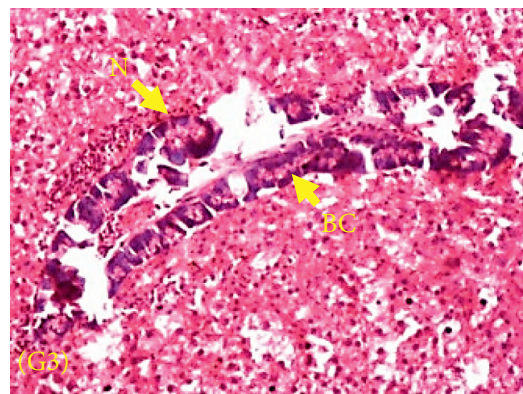

(k)

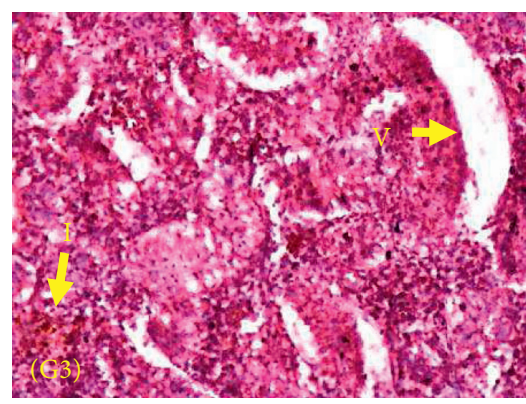

(c)

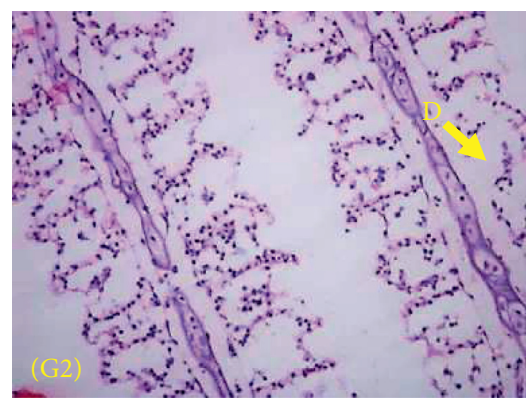

(f)

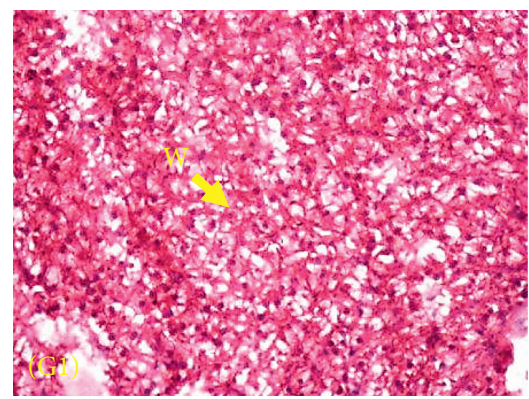

(i)

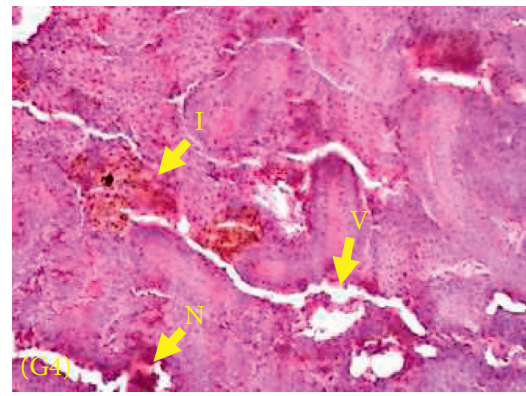

(l)

Figure 4: (a-d) Histology of kidney. G1 showed normal structure of renal tubules (RT) and renal hematopoietic tissue (RHT). G2 kidney showed glomerulus shrinkage (GS), G3 vacuolation (V) and inflammation (I), and G4 necrosis (N) and epithelial desquamation (ED). (e-h) Histology of gills. G1 showed normal structure of gills, gill filament (GF), and gill lamella (GL). G3-G4 showed degeneration (D), lamellar fusion (LF), hemorrhage (H), blood congestion (BC), lamellar disorganization (LD), and lamellar aneurysm (LA). Histology of liver. Hepatocytes (H), vacuolation (V), necrosis (N), blood congestion (BC), and inflammation (I) (G1: control, G2: 1 mg/l, G3: 10 mg/l, and G4: $20 \mathrm{mg} / \mathrm{l})$. Images were captured at 40x.

under stressful conditions of nanoparticles' exposure which lead to growth reduction [43].

Hematological parameters are routinely used to ascertain toxicant related stress in aquatic animals $[44,45]$. In our study, we observed significant decline in RBCs, WBCs, $\mathrm{Hb}$, and $\mathrm{Hct} \%$ values in AsNPs treated groups at higher concentrations (Table 4). Lower values of blood cell counts, $\mathrm{Hb}$, and $\mathrm{Hct} \%$ are signpost of blood disorders in the treated fish. At high concentrations, gold NPs caused low TEC and Hct\% levels in mice [43]. In another study, zinc oxide nanoparticles at sublethal concentrations caused low $\mathrm{Hb}$, TECs, and Hct\% in Oreochromis niloticus [46]. Furthermore, 
a one-week exposure of silver nanoparticles caused significant reduction in TECs and Hct\% in silver carp [47]. AsNPs have been reported to induce apoptosis in hepatocytes [48]. In their recent work, they reported that both As and AsNPs significantly destruct lysosomal membrane integrity and decrease mitochondrial membrane potential in hepatocytes. However, the extent of damage to lysosomal and mitochondrial membranes was significantly high in AsNPs treated cells as compared to bulk As. Impaired hematological parameters reflect underlying disease conditions and imbalanced immune response in fish.

Protein biomarkers are critical indicators of physiological disturbances. TP and GLB are used to measure index of specific immune responses $[49,50]$. We found that TP and globulin were significantly low in AsNPs treated groups at higher concentrations. Serum proteins have been found to decrease in response to toxicants' stress [5]. Reduction in protein levels suggests that they have been consumed as substitute energy source to fulfil high energy requirement in NPs treated fish. This might be due to NPs mediated stress which reduces appetite and results in reduced nutritional/ serum protein values. Hemodilution may also cause loss, low synthesis, or reduced absorption of proteins [50,51]. ALB is important for steroid hormone regulation [52]. Higher levels of ALB were found in treated fish. Significant increase in ALB was found in liver and muscles of Channa punctatus exposed to $\mathrm{Cr}, \mathrm{Ni}$, and $\mathrm{Co}$ [53].

Although low concentrations of AsNPs did not provoke a strong difference in the antioxidant enzyme activities (catalase and SOD), at higher concentrations (G3 and G4) enzyme activities were reduced in treated groups. Antioxidant enzymes protect cells against ROS (reactive oxygen species). A high antioxidant activity ensures less oxidative stress $[54,55]$. Antioxidant enzymes have also been used to study oxidative stress in aquatic animals $[56,57]$. Low amount of antioxidant enzymes leads to retarded metabolic enzymes and cellular injury [58].

Kidney, gills, and liver are the major sites for metabolism and detoxification of foreign molecules. Upon disturbance of normal structure of these organs via pollutants, all other important processes of the body may get disrupted. Our histopathological results showed that kidney, gills, and liver were affected by AsNPs. Extensive abnormalities were found in G3 and G4 groups. Similar to our findings, $\mathrm{TiO}_{2} \mathrm{NPs}$ have been reported to cause apoptosis in zebrafish head and tail [59]. Histopathological lesions in gills and liver of Siberian sturgeon were found upon exposure to CuNPs and AgNPs [60]. The overall deformations in these organs may be allied to protein imbalance, oxidative stress, DNA damage, and necrosis [61, 62]. From this study, we conclude that AsNPs at higher concentrations are toxic to aquatic organisms. It causes behavior modification, growth retardation, hematological disorders, and immunobiochemical and histological defects in Labeo rohita fish. The findings of this work can be useful for better health management in aquaculture. It will help in early disease detection and control in fish. The advances in toxicity evaluation will help to improve fish growth and production bringing economic benefits to farmers.

\section{Conclusions}

In summary, chemically synthesized AsNPs having spherical shape and size distribution of $40 \pm 10 \mathrm{~nm}$ were tested for different toxic effects on Labeo rohita juveniles for 30 days' exposure period. Alterations in different parameters, such as growth, behavior, blood profiling, biochemical factors, and tissue structure damage, clearly demonstrated the toxic impact of AsNPs on treated fish as compared to untreated control. Based on the findings of this work, we propose that L. rohita can be used as a potential bioindicator for assessment of induced nanotoxicity. Furthermore, before use of AsNPs for various practical applications, their toxic potential must cautiously be evaluated.

\section{Data Availability}

All the data and references cited to support our results are available and can be provided upon demand.

\section{Conflicts of Interest}

The authors declare no conflicts of interest regarding the publication of this paper.

\section{Acknowledgments}

This work was financially supported by Higher Education Commission (HEC) of Pakistan under the Project of National Research Program for Universities (Project no. HECNRPU-8019). The authors are grateful to Himalaya Fish Hatchery Muridke Lahore for providing Labeo rohita juveniles and HEC for providing the financial support.

\section{References}

[1] C. Dautremepuits, S. Paris-Palacios, S. Betoulle, and G. Vernet, "Modulation in hepatic and head kidney parameters of carp (Cyprinus carpio L.) induced by copper and chitosan," Comparative Biochemistry and Physiology - Part C: Toxicology \& Pharmacology, vol. 137, no. 4, pp. 325-333, 2004.

[2] A. Chatterjee, D. Das, and D. Chakraborti, "A study of ground water contamination by arsenic in the residential area of Behala, Calcutta due to industrial pollution," Environmental Pollution, vol. 80, no. 1, pp. 57-65, 1993.

[3] S. M. Adams and M. S. Greeley, "Ecotoxicological indicators of water quality: using multi-response indicators to assess the health of aquatic ecosystems," Environmental Challenges, vol. 123, pp. 103-115, 2000.

[4] M. L. Carvalho, S. Santiago, and M. L. Nunes, "Assessment of the essential element and heavy metal content of edible fish muscle," Analytical and Bioanalytical Chemistry, vol. 382, no. 2, pp. 426-432, 2005.

[5] B. Aruljothi, M. Sivanandan, and S. Sankar Samipillai, "Effect of arsenic on protein and carbohydrate metabolism of fresh water fish, Labeo rohita," International Journal of Current Research, vol. 5, no. 5, pp. 1332-1335, 2013.

[6] S. Bayda, M. Adeel, T. Tuccinardi, M. Cordani, and F. Rizzolio, "The history of nanoscience and nanotechnology: from chemical-physical applications to nanomedicine," Molecules, vol. 25, no. 1, p. 112, 2020. 
[7] M. Raza, Z. Kanwal, A. Rauf, A. Sabri, S. Riaz, and S. Naseem, "Size- and shape-dependent antibacterial studies of silver nanoparticles synthesized by wet chemical routes," Nanomaterials, vol. 6, no. 4, p. 74, 2016.

[8] M. Saravanan, R. Suganya, M. Ramesh, R. K. Poopal, N. Gopalan, and N. Ponpandian, "Iron oxide nanoparticles induced alterations in haematological, biochemical and ionoregulatory responses of an Indian major carp Labeo rohita," Journal of Nanoparticle Research, vol. 17, Article ID 274, 2015.

[9] C. Jayaseelan, A. Abdul Rahuman, R. Ramkumar et al., "Effect of sub-acute exposure to nickel nanoparticles on oxidative stress and histopathological changes in Mozambique tilapia, Oreochromis mossambicus," Ecotoxicology and Environmental Safety, vol. 107, pp. 220-228, 2014.

[10] K. S. Rajkumar, N. Kanipandian, and R. Thirumurugan, "Toxicity assessment on haemotology, biochemical and histopathological alterations of silver nanoparticles-exposed freshwater fish Labeo rohita," Applied Nanoscience, vol. 6, no. 1, pp. 19-29, 2016.

[11] Y. Tahereh, S. Issa, S. Mehdi, and E. Hamed K, "Evaluation of silver retention in different organs of zebrafish (danio rerio) fed diet supplemented with silver nanoparticles," International Journal of Engineering Research, vol. 5, no. 4, pp. 269-274, 2016.

[12] B. Mansouri, A. Maleki, S. Ali Johari, and N. Reshahmanish, "Effects of cobalt oxide nanoparticles and cobalt ions on gill histopathology of zebrafish (Danio rerio)," AACL Bioflux, vol. 8, pp. 438-444, 2015.

[13] Z. Kanwal, M. Raza, F. Manzoor et al., "A comparative assessment of nanotoxicity induced by metal (silver, nickel) and metal oxide (cobalt, chromium) nanoparticles in Labeo rohita," Nanomaterials, vol. 9, no. 2, p. 309, 2019.

[14] A. Subastri, V. Arun, P. Sharma et al., "Synthesis and characterisation of arsenic nanoparticles and its interaction with DNA and cytotoxic potential on breast cancer cells," ChemicoBiological Interactions, vol. 295, pp. 73-83, 2018.

[15] Y. Wang, Y. Dong, Y. Liu, and Z. Liu, "Arsenic trioxide nanoparticles inhibit acute promyelocytic leukemia cell proliferation and induce apoptosis via PTEN/AKT signalling pathway," Biomedical Research, vol. 29, no. 7, pp. 1450-1454, 2018.

[16] X. Dong, N. Ma, M. Liu, and Z. Liu, "Effects of As2O3 nanoparticles on cell growth and apoptosis of NB4 cells," Experimental and Therapeutic Medicine, vol. 10, no. 4, pp. 1271-1276, 2015.

[17] Us Epa, "National primary drinking water regulations; arsenic and clarifications to compliance and new source contaminants monitoring" from the environmental protection agency; final rule," Federal Register, vol. 66, pp. 6976-7066, 2001.

[18] H. O. Gonzalez, J. A. Roling, W. S. Baldwin, and L. J. Bain, "Physiological changes and differential gene expression in mummichogs (Fundulus heteroclitus) exposed to arsenic," Aquatic Toxicology, vol. 77, no. 1, pp. 43-52, 2006.

[19] S. Das, B. Unni, M. Bhattacharjee, S. B. Wann, and P. G. Rao, "Toxicological effects of arsenic exposure in a fresh water teleost fish, Channa punctatus," African Journal of Biotechnology, vol. 11, no. 19, pp. 4447-4454, 2012.

[20] K. Pazhanisamy and N. Indra, "Toxic effects of arsenic on protein content in the fish, Labeo rohita, (Hamilton)," Nature Environment and Pollution Technology, vol. 6, no. 1, pp. 113-116, 2007.

[21] N. Humtsoe, R. Davoodi, B. G. Kulkarni, and B. Chavan, "Effect of arsenic on the enzymes of the Rohu carp, Labeo rohita (Hamilton, 1822)," Raffles Bulletin of Zoology, vol. 14, pp. 17-19, 2007.

[22] A. Amsath, J. Sugumaran, and S. Vanitha, "Effect of arsenic $\left(\mathrm{As}_{2} \mathrm{O}_{3}\right)$ on hematological parameters of freshwater air breathing fish, Channa punctatus (bloch)," Current Trends in Biomedical Engineering \& Biosciences, vol. 7, no. 1, pp. 3-7, 2017.

[23] M.-D. Luh, R. A. Baker, and D. E. Henley, "Arsenic analysis and toxicity-a review," The Science of the Total Environment, vol. 2, no. 1, pp. 1-12, 1973.

[24] S. Bal, A. Yadav, N. Verma, R. Gupta, and N. K. Aggarwal, "Shielding effect of anethole against arsenic induced genotoxicity in cultured human peripheral blood lymphocytes and effect of GSTO1 polymorphism," 3 Biotech, vol. 8, Article ID 232, 2018.

[25] A. Ivanc, E. Hasković, S. Jeremić, and R. Dekić, "Hematological evaluation of welfare and health of fish," Praxis veterinaria, vol. 53, pp. 191-202, 2005.

[26] O. Eriegha, B. Omitoyin, and E. Ajani, "Evaluation of haematological and biochemical parameters of juvenile oreochromis niloticus after exposure to water soluble fractions of crude oil," Journal of Applied Sciences \& Environmental Management, vol. 21, no. 6, pp. 1041-1045, 2017.

[27] Ü. Acer, C. Saoca, O. S. Kesbiç, S. Yilmaz, M. Yiğit, and B. E. İnanan, "Comparative study on haematological and biochemical parameters of two wild sparid fish species," Cahiers de Biologie Marine, vol. 60, pp. 51-57, 2019.

[28] Z. Kanwal, M. A. Raza, F. Manzoor et al., "In vivo antiproliferative activity of silver nanoparticles against Pseudomonas aeruginosa in freshwater Labeo rohita," Applied Nanoscience, vol. 9, no. 8, pp. 2039-2049, 2019.

[29] A. Pal, S. Saha, S. K. Maji, M. Kundu, and A. Kundu, "Wetchemical synthesis of spherical arsenic nanoparticles by a simple reduction method and its characterization," Advanced Materials Letters, vol. 3, no. 3, pp. 177-180, 2012.

[30] J. V. Dacie and S. M. Lewis, Practical Haematologypp. 37-85, ELBS with Churchill Livingston, London, 7th edition, 1991.

[31] M. A. Raza, A. Habib, Z. Kanwal et al., "Optical $\mathrm{CO}_{2}$ gas sensing based on $\mathrm{TiO}_{2}$ thin films of diverse thickness decorated with silver nanoparticles," Advances in Materials Science and Engineering, vol. 2018, Article ID 2780203, 12 pages, 2018.

[32] S. Rasool, M. A. Raza, F. Manzoor et al., "Biosynthesis, characterization and anti-dengue vector activity of silver nanoparticles prepared from Azadirachta indica and Citrullus colocynthis," Royal Society Open Science, vol. 7, no. 9, Article ID 200540, 2020.

[33] J. K. Patra and K.-H. Baek, "Green nanobiotechnology: factors affecting synthesis and characterization techniques," Journal of Nanomaterials, vol. 2014, Article ID 417305, 2014.

[34] H. E. Swanson, R. K. Fuyat, and G. M. Ugrinic, "Standard X-ray diffraction powder patterns," National Bureau of Standards Circular, vol. 539, no. III, 6 pages, 1954.

[35] S. Riaz, M. Bashir, M. Akram Raza, A. Mahmood, and S. Naseem, "Effect of calcination on structural and magnetic properties of Co-doped $\mathrm{ZnO}$ nanostructures," IEEE Transactions on Magnetics, vol. 51, no. 11, pp. 1-4, 2015.

[36] V. De Matteis, "Exposure to inorganic nanoparticles: routes of entry, immune response, biodistribution and in vitro/in vivo toxicity evaluation," Toxics, vol. 5, no. 4, p. 29, 2017.

[37] W. O. Smith Jr, J. Marra, M. R. Hiscock, and R. T. Barber, "The seasonal cycle of phytoplankton biomass and primary productivity in the Ross Sea, Antarctica," Deep Sea Research Part II: Topical Studies in Oceanography, vol. 47, no. 15-16, pp. 3119-3140, 2000. 
[38] K. Mattsson, E. V. Johnson, A. Malmendal, S. Linse, L. A. Hansson, and T. Cedervall, "Brain damage and behavioural disorders in fish induced by plastic nanoparticles delivered through the food chain," Scientific Reports, vol. 7, Article ID 11452, 2017.

[39] C. Smith, B. Shaw, and R. Handy, "Toxicity of single walled carbon nanotubes to rainbow trout, (Oncorhynchus mykiss): respiratory toxicity, organ pathologies, and other physiological effects," Aquatic Toxicology, vol. 82, no. 2, pp. 94-109, 2007.

[40] T. Cedervall, L. A. Hansson, M. Lard, B. Frohm, and S. Linse, "Food chain transport of nanoparticles affects behavior and fat metabolism," PLoS One, vol. 7, no. 2, Article ID e32254, 2012.

[41] J. A. Kovriznych, R. Sotnikova, D. ZeljenKova, E. Rollerova, E. Szabova, and S. Wimmerova, "Acute toxicity of 31 different nanoparticles to zebrafish (Danio rerio) tested in adulthood and in early life stages-comparative study," Interdisciplinary Toxicology, vol. 6, no. 2, pp. 67-73, 2013.

[42] H.-Y. Zhang, R.-L. Chen, Y. Shao, H.-L. Wang, and Z.-G. Liu, "Effects of exposure of adult mice to multi-walled carbon nanotubes on the liver lipid metabolism of their offspring," Toxicology Research, vol. 7, no. 5, pp. 809-816, 2018.

[43] X. D. Zhang, H. Y. Wu, D. Wu et al., "Toxicologic effects of gold nanoparticles in vivo by different administration routes," International Journal of Nanomedicine, vol. 5, pp. 771-781, 2010.

[44] A. Ciji, N. P. Sahu, A. K. Pal, S. Dasgupta, and M. S. Akhtar, "Alterations in serum electrolytes, antioxidative enzymes and haematological parameters of Labeo rohita on short-term exposure to sublethal dose of nitrite," Fish Physiology and Biochemistry, vol. 38, no. 5, pp. 1355-1365, 2012.

[45] P. C. Das, S. Ayyappan, J. K. Jena, and B. K. Das, "Nitrite toxicity in Cirrhinus mrigala (Ham.): acute toxicity and sublethal effect on selected haematological parameters," Aquaculture, vol. 235, no. 1-4, pp. 633-644, 2004.

[46] A. Alkaladi, N. A. M. N. El-Deen, M. Afifi, and O. A. A. Zinadah, "Hematological and biochemical investigations on the effect of vitamin $\mathrm{E}$ and $\mathrm{C}$ on Oreochromis niloticus exposed to zinc oxide nanoparticles," Saudi Journal of Biological Sciences, vol. 22, no. 5, pp. 556-563, 2015.

[47] F. Shaluei, A. Hedayati, A. Jahanbakhshi, H. Kolangi, and M. Fotovat, "Effect of subacute exposure to silver nanoparticle on some hematological and plasma biochemical indices in silver carp (Hypophthalmichthys molitrix)," Human \& Experimental Toxicology, vol. 32, no. 12, pp. 1270-1277, 2013.

[48] R. Jahangirnejad, M. Goudarzi, H. Kalantari, H. Najafzadeh, and M. Rezaei, "Subcellular organelle toxicity caused by arsenic nanoparticles in isolated rat hepatocytes," The International Journal of Occupational and Environmental Medicine, vol. 11, no. 1, pp. 41-52, 2020.

[49] S. Maqsood, M. H. Samoon, and P. Singh, "Immunomodulatory and growth promoting effect of dietary levamisole in Cyprinus carpio fingerlings against the challenge of Aeromonas hydophila," Turkish Journal of Fisheries and Aquatic Sciences, vol. 9, pp. 111-120, 2009.

[50] M. Stosik, W. Deptula, and M. Trávniček, "Resistance in carps (Cyprinus carpio L.) affected by a natural bacterial infection," Veterinarni Medicina, vol. 46, no. No. 1, pp. 6-11, 2001.

[51] T. Patriche, N. Patriche, E. Bocioc, and M. T. Coada, "Serum biochemical parameter of farmed carp (C. carpio)," AACL Bioflux, vol. 4, pp. 131-140, 2011.

[52] D. Shahsavani, H. R. Kazerani, S. Kaveh, and H. GholipourKanani, "Determination of some normal serum parameters in starry sturgeon (Acipenser stellatus Pallas, 1771) during spring season," Comparative Clinical Pathology, vol. 19, no. 1, pp. 57-61, 2010.

[53] M. Javed and N. Usmani, "Stress response of biomolecules (carbohydrate, protein and lipid profiles) in fish Channa punctatus inhabiting river polluted by Thermal Power Plant effluent," Saudi Journal of Biological Sciences, vol. 22, no. 2, pp. 237-242, 2015.

[54] D. Fournier, J. M. Bride, M. Poirie, J. B. Bergé, and F. W. Plapp, "Insect glutathione S-transferases. Biochemical characteristics of the major forms from houseflies susceptible and resistant to insecticides," Journal of Biological Chemistry, vol. 267 , no. 3, pp. 1840-1845, 1992.

[55] V. I. Lushchak and T. V. Bagnyukova, "Effects of different environmental oxygen levels on free radical processes in fish," Comparative Biochemistry and Physiology Part B: Biochemistry and Molecular Biology, vol. 144, no. 3, pp. 283-289, 2006.

[56] S. E. Sabatini, G. Chaufan, Á. B. Juárez et al., "Dietary copper effects in the estuarine crab, Neohelice (Chasmagnathus) granulata, maintained at two different salinities," Comparative Biochemistry and Physiology - Part C: Toxicology \& Pharmacology, vol. 150, no. 4, pp. 521-527, 2009.

[57] J. Dorts, F. Silvestre, H. T. Tu, A.-E. Tyberghein, N. T. Phuong, and P. Kestemont, "Oxidative stress, protein carbonylation and heat shock proteins in the black tiger shrimp, Penaeus monodon, following exposure to endosulfan and deltamethrin," Environmental Toxicology and Pharmacology, vol. 28, no. 2, pp. 302-310, 2009.

[58] C. R. Hunt, J. E. Sim, S. J. Sullivan et al., "Genomic instability and catalase gene amplification induced by chronic exposure to oxidative stress," Cancer Research, vol. 58, pp. 3986-3992, 1998.

[59] S. Mozaffari, W. Li, C. Thompson et al., "Colloidal nanoparticle size control: experimental and kinetic modeling investigation of the ligand-metal binding role in controlling the nucleation and growth kinetics," Nanoscale, vol. 9, no. 36, pp. 13772-13785, 2017.

[60] T. Ostaszewska, M. Chojnacki, M. Kamaszewski, and E. Sawosz-Chwalibóg, "Histopathological effects of silver and copper nanoparticles on the epidermis, gills, and liver of Siberian sturgeon," Environmental Science and Pollution Research, vol. 23, no. 2, pp. 1621-1633, 2016.

[61] V. Sanchez-Valle, N. C. Chavez-Tapia, M. Uribe, and N. Mendez-Sanchez, "Role of oxidative stress and molecular changes in liver fibrosis: a review," Current Medicinal Chemistry, vol. 19, no. 28, pp. 4850-4860, 2012.

[62] M. Mela, M. A. F. Randi, D. F. Ventura, C. E. V. Carvalho, E. Pelletier, and C. A. Oliveira Ribeiro, "Effects of dietary methylmercury on liver and kidney histology in the neotropical fish Hoplias malabaricus," Ecotoxicology and Environmental Safety, vol. 68, no. 3, pp. 426-435, 2007. 